\title{
Aplicação de silício via solo no rendimento e na qualidade fisiológica de sementes de soja
}

\author{
Silicon application to the soil on soybean yield and seed \\ physiological quality
}

\author{
Sandro de Oliveira ${ }^{1 *}$; Elisa Souza Lemes ${ }^{1}$; Géri Eduardo Meneghello ${ }^{2}$; \\ Lizandro Ciciliano Tavares ${ }^{1}$; Antonio Carlos Souza Albuquerque Barros ${ }^{3}$
}

\section{Resumo}

A utilização de sementes de qualidade, a equilibrada nutrição das plantas e a adoção de técnicas adequadas de cultivo são fundamentais para o sucesso da lavoura. O uso de silício ( $\mathrm{Si}$ ) é uma tecnologia limpa do ponto de vista ambiental, que pode conferir vários benefícios para as plantas como estimular o crescimento e a produção vegetal, proporcionar maior tolerância das plantas ao ataque de insetos e doenças, reduzir a transpiração e aumentar a taxa fotossintética e, proteger contra estresses abióticos. O objetivo do trabalho foi avaliar o efeito da aplicação de Si oriundo da cinza de casca de arroz carbonizada, via solo, nas características agronômicas, na produtividade e na qualidade fisiológica das sementes de cultivares de soja. $\mathrm{O}$ experimento foi conduzido em vasos de $18 \mathrm{~L}$ preenchidos com solo, sob o delineamento experimental de blocos casualizados, com quatro repetições. As cultivares de soja utilizadas foram BMX Turbo RR e NA 5909 RR, cultivadas sob cinco doses de silício via solo (0, 1, 2, 3 , e $4 \mathrm{t} \mathrm{ha}^{-1}$ ). Foram avaliadas as características agronômicas e o rendimento de sementes (número total de legumes nos ramos, número total de sementes nos ramos, número total de legumes na haste principal, número total de sementes na haste principal, número total de legumes por planta, número total de sementes por planta, massa de sementes por planta e massa de 1000 sementes). A qualidade fisiológica das sementes foi avaliada pelos testes de germinação e de vigor (primeira contagem da germinação, teste de frio, envelhecimento acelerado, comprimento da parte aérea e da raiz). A aplicação de silício via solo é benéfico para a cultura da soja, melhorando as principais características agronômicas (número total de legumes nos ramos, número total de sementes nos ramos, número total de legumes por planta, massa de sementes por planta) e aumentando o rendimento de sementes por planta na cultivar de soja BMX Turbo RR. A massa de mil sementes é influenciada positivamente até a dose de 1,67 tha ${ }^{-1}$ para a cultivar BMX Turbo RR e até a dose de 2,32 $\mathrm{t} \mathrm{ha}^{-1}$ para a cultivar NA $5909 \mathrm{RR}$. O vigor das sementes da cultivar BMX Turbo RR é incrementado com o uso de silício via solo.

Palavras-chave: Glycine $\max$ (L. Merrill), nutrição, produtividade, viabilidade

\begin{abstract}
Use of quality seeds, balanced plant nutrition and the adoption of adequate cultivation techniques are critical to the success of the soybean crop. Use of silicon ( $\mathrm{Si}$ ) is a clean technology from an environmental point of view, which can confer several benefits to the plants as stimulate growth and plant production, improve tolerance of plants to attack by insects and diseases, reduce perspiration and increase the

1 Discentes do Curso de Doutorado do Programa de Pós Graduando do Curso de Ciência e Tecnologia de Sementes, Universidade Federal de Pelotas, UFPel, Pelotas, RS. E-mail: sandrofaem@yahoo.com.br; lemes.elisa@yahoo.com.br; lizandro_ cicilianotavares@yahoo.com.br

2 Dr. em Ciência e Tecnologia em Sementes, UFPel, Pelotas, RS. E-mail: gmeneghello@gmail.com

3 Prof. Dr., Curso de Pós-Graduação de Ciência e Tecnologia de Sementes, UFPel, Pelotas, RS. E-mail: acbarros@ufpel.edu.br
\end{abstract}

* Autor para correspondência 
photosynthetic rate and protect against abiotic stresses. The goal was to evaluate the effect of soil $\mathrm{Si}$ application derived from rice husk ash on the agronomic characteristics, productivity and physiological quality of soybean cultivars seeds. The experiment was conducted in pots of $18 \mathrm{~L}$ filled with soil, under a randomized block design with four replications. The soybean cultivars were BMX Turbo RR and NA $5909 \mathrm{RR}$, grown under five doses of silicon $\left(0,1,2,3\right.$, and $\left.4 \mathrm{t} \mathrm{ha}^{-1}\right)$. Agronomic traits and seed yield were evaluated (total number of pods on branches, total number of seeds on the branches, the total number of pods on the main stem, total number of seeds on the main stem, total number of pods per plant, total number of seeds per plant, seed weight per plant and seed weight of 1000). Physiological seed quality was evaluated by germination and vigor tests (first count of germination, cold test, accelerated aging, shoot length and root). The soil application of silicon is beneficial for the soybean crop, improving the main agronomic characteristics (total number of pods on branches, total number of seeds in the branches, total number of pods per plant, weight of seeds per plant) and increasing seed yield per plant in soybean cultivar BMX Turbo RR. The mass of a thousand seeds is positively influenced by the dose of $1.67 \mathrm{tha}^{-1}$ for the cultivar BMX Turbo RR and up to a dose of $2.32 \mathrm{tha}^{-1}$ for the cultivar NA $5909 \mathrm{RR}$. Cultivar BMX Turbo RR seed vigor is increased with the use of silicon in the soil.

Key words: Glycine $\max$ (L. Merril), nutrition, productivity, viability

\section{Introdução}

A soja é uma cultura amplamente cultivada e de grande importância no Brasil. Na safra 2014/2015 ocupou uma área de aproximadamente 31,3 milhões de hectares, com uma produção de 93 milhões de toneladas (CONAB, 2015). Devido aos grandes volumes comercializados para o mercado externo, aliado à redução na produção de outros países produtores de soja, decorrente de adversidades climáticas, o preço desta commodity alcançou valores recordes. Diante da demanda, há interesse dos produtores em aprimorar as técnicas de produção, buscando alternativas para que se atinja o máximo de produção com o mínimo de impacto ambiental.

Nesse sentido umas das etapas importantes, se não a mais, é a utilização de sementes de alta qualidade, pois de acordo com Kolchinski, Schuch e Peske $(2005,2006)$ sementes de soja com alta qualidade fisiológica proporcionarão plantas com maiores taxas de crescimento inicial e eficiência metabólica, maior área foliar, maior produção de matéria seca e maiores rendimentos, aumentando assim as chances de sucesso da lavoura.

Segundo Carvalho e Nakagawa (2000), a produção e a qualidade fisiológica das sementes é diretamente dependente da disponibilidade de nutrientes na lavoura, por afetar a formação do embrião e dos órgãos de reserva, assim como a composição química e, consequentemente, o metabolismo e o vigor das mesmas. De acordo com Sá (1994), plantas bem nutridas podem produzir maior número de sementes com melhor qualidade fisiológica, uma vez que podem tornar-se mais tolerantes às adversidades climáticas, como o deficit hídrico.

Os elementos com funções especificas e essenciais no metabolismo das plantas são classificados geralmente em dois grupos, os macronutrientes e os micronutrientes, em relação as suas concentrações na planta conforme são requeridos para crescimento e reprodução adequadas (MALAVOLTA, 2006; MARSCHNER, 1995). Existem ainda os elementos benéficos, que são essenciais somente para certas espécies ou sob condições específicas. Os elementos benéficos, são aqueles minerais que compensam ou eliminam os efeitos tóxicos de outros, substituem um elemento essencial em alguma de suas funções menos específicas e são exigidos por alguns grupos de plantas ou ainda por plantas em circunstâncias peculiares, (SANTOS, 2004).

Apesar de não ser um elemento essencial para as plantas, o Si pode estimular o crescimento e a produção vegetal por meio de várias ações indiretas, como maior tolerância das plantas ao ataque de insetos e doenças, devido a ativação de mecanismos 
de defesa da plantas em resposta à invasão dos patógenos (CHÉRIF; ASSELIN; BELEANGER, 1994). Pode reduzir a transpiração e favorecer a taxa fotossintética das plantas, devido a melhoria da arquitetura foliar (REIS et al., 2007), e diminuir o auto-sombreamento por proporcionar folhas mais eretas. Além disso, pode proporcionar maior tolerância ao acamamento e maior rigidez estrutural dos tecidos, proteção contra estresses abióticos, como a redução da toxicidez de manganês, ferro e sódio (EPSTEIN, 1994; MARSCHNER, 1995), aumentar a resistência das plantas ao excesso de alumínio (WIESE; NIKOLIC; RÖMEHELD, 2007), podendo ainda estar envolvido em atividades metabólicas ou fisiológicas das plantas sob estresse salino e/ou hídrico (GUNES et al., 2008).

O Si é absorvido pela planta na forma de ácido monossilícico $\left(\mathrm{H}_{4} \mathrm{SiO}_{4}\right)$ juntamente com a água, através de um processo regulado pela transpiração e se acumula principalmente nas áreas de máxima transpiração, como ácido silícico polimerizado. Em geral, são consideradas plantas acumuladoras de $\mathrm{Si}$, aquelas que possuem teor foliar acima de $1 \%$, e não acumuladoras plantas com teor de silício inferior a $0,5 \%$ (MA; MIYAKE; TAKAHASHI, 2001), sendo a soja considerada como planta não acumuladora. A concentração de $\mathrm{SiO} 2$ extraível nos solos varia de menos de 1 até mais de $100 \mathrm{mg}$ $\mathrm{dm}^{-3}$ (RAVEN, 1983) em função dos teores de argila (RAIJ; CAMARGO, 1973), dos teores de óxidos de ferro e alumínio (FREITAS et al., 1977) e do pH (BECKWITH; REEVE, 1963). Dentre esses fatores, o $\mathrm{pH}$ do solo é um fator importante, pois pode ser alterado com o manejo dos solos, enquanto os outros são intrínsecos de cada tipo de solo, sendo que várias classes de solos possuem alto grau de intemperismo, baixo $\mathrm{pH}$ e são pobres em silício e nutrientes, sendo dependentes da correção química (PEREIRA et al., 2004).

$\mathrm{Na}$ soja a adubação com silicato promoveu aumentos no número de legumes por planta, altura de plantas (PEREIRA JUNIOR et al., 2010) e, quando observado sintomas de deficiência de Si, são verificados má formação de folhas novas e redução da fertilidade dos grãos de pólen (MYAKE; TAKASHI, 1985). De acordo com Mori et al. (2006), os principais fatores limitantes à produtividade das lavouras de soja, são os fatores climáticos, seguido por danos causados por doenças e insetos, porém estes últimos podem ser minimizados com a aplicação de produtos recomendados.

O objetivo do trabalho foi avaliar o efeito da aplicação de $\mathrm{Si}$ oriundo da cinza de casca de arroz carbonizada via solo nas características agronômicas, no rendimento e na qualidade fisiológica das sementes de cultivares de soja.

\section{Material e Métodos}

Os experimentos foram desenvolvidos na Área Experimental e no Laboratório Didático de Análise de Sementes (LDAS), ambos pertencentes ao Programa de Pós-Graduação Ciência e Tecnologia de Sementes (FAEM/UFPel). Foram utilizadas sementes de soja das cultivares BMX Turbo RR (hábito de crescimento indeterminado, grupo de maturação 5,8 com ciclo de 130 dias) e NA 5909 RR (hábito de crescimento indeterminado, grupo de maturação 5,9, ciclo aproximado entre 115 a 130 dias). Os experimentos foram conduzidos separadamente para cada cultivar, com aplicação de Si via solo, utilizando como fonte a cinza da casca de arroz carbonizada, com delineamento experimental de blocos casualizados, com quatro repetições.

Para a aplicação da fonte de $\mathrm{Si}$, foi utilizado o equivalente a $0,1,2,3$ e $4 \mathrm{t}$ de $\mathrm{Si}_{\text {ha }}{ }^{-1}$. Para tanto, considerou-se o volume da camada arável do solo em um ha em torno de 2 milhões de L, sendo então, esta quantidade transformada para o volume dos vasos, os quais foram preenchidos com 18 litros de solo. Foi utilizado o equivalente a 0 ; 9,78; 19,56;29,35 e 39,13 g de cinza de casca de arroz carbonizada, referente a cada dose, em cada vaso. A aplicação da cinza de casca de arroz foi realizada no momento da semeadura e incorporada ao solo até uma profundidade de $0,1 \mathrm{~m}$, pois nesta 
concentra-se a maior parte das raízes. A cinza de casca de arroz apresenta aproximadamente 92\% de óxido de silício, sendo os outros $8 \%$ compostos por nitrogênio, fósforo, potássio, cálcio, magnésio, ferro e manganês

Previamente à semeadura, as sementes foram tratadas com o fungicida MAXIM XL ${ }^{\circledR}$, (Metalaxyl-M + Fludioxonil), inseticida CRUISER 350 FS $^{\circledR}$ (Tiametoxam) e polímero líquido Sepiret 9241 B Green utilizando-se 100, 200 e $400 \mathrm{~mL}$ $100 \mathrm{~kg}$ de sementes ${ }^{-1}$, respectivamente, com um volume de calda de $800 \mathrm{~mL} 100 \mathrm{~kg}$ de sementes ${ }^{-1}$, o qual foi completado com água. O recobrimento foi realizado seguindo a metodologia utilizada por Nunes (2005), que consiste num método manual em sacos plásticos.

Em seguida foi realizada a semeadura das sementes nos vasos, os quais foram preenchidos com solo peneirado, coletado do horizonte A1 de um Planossolo Háplico eutrófico solódico (STRECK et al., 2008), pertencente à unidade de mapeamento Pelotas. Foi realizada uma análise de solo, a qual indicava os seguintes valores: teor de argila: $24 \%$; índice SMP: 6,0; MO: 2,0\%; P 10,3 $\mathrm{mg} \mathrm{dm}^{-3}$; K: 62,5 $\mathrm{mg} \mathrm{dm}{ }^{-3}$. A adubação foi realizada de acordo com os resultados da análise de solo e recomendações da Comissão de Química e Fertilidade do Solo - RS/ SC (CQFS, 2004). Foram semeadas 10 sementes por vaso, sendo que após a emergência foi realizado desbaste deixando apenas três plantas por vaso, as quais permaneceram até a colheita das sementes.

A irrigação foi realizada diariamente, sendo o experimento mantido até o estádio genealógico R7 segundo escala de Fehr e Caviness (1977). Durante o crescimento e desenvolvimento das plantas foram realizadas aplicações de fungicidas e inseticidas, de maneira preventiva, com uma aplicação no início do florescimento (R1) e uma no enchimento de grãos (R5), também foi aplicado acaricida, devido ao surgimento da praga.

Para as avaliações das características agronômicas foram avaliadas as três plantas por vaso, onde separaram-se manualmente os ramos da haste principal, determinando-se assim, através de contagem direta, o número total de legumes nos ramos ( $\left.\mathrm{N}^{\circ} \mathrm{TLR}\right)$ e o número total de sementes nos ramos ( $\left.\mathrm{N}^{\circ} \mathrm{TSR}\right)$. Da mesma forma, foi contando o número total de legumes na haste principal ( $\mathrm{N}^{\circ}$ TLHP), número total de sementes na haste principal ( $\left.{ }^{\circ} \mathrm{TSHP}\right)$, obtendo dessa forma o número total de legumes por planta ( $\left.{ }^{\circ} \mathrm{TLP}\right)$, número total de sementes por planta ( $\left.{ }^{\circ} \mathrm{TSP}\right)$ e massa de sementes por planta (PSP).

As sementes estavam com teor de água de $13 \%$ quando avaliado a qualidade fisiológica das sementes, a qual foi avaliada mediante os seguintes testes: Teste de germinação $(\mathrm{G})$ : realizado segundo as Regras para Análise de Sementes - RAS (BRASIL, 2009), por meio da semeadura de 200 sementes, divididas em quatro sub amostras de 50 sementes para cada repetição, em rolo de papel tipo germitest umedecido, previamente, com água destilada na proporção de 2,5 vezes a massa do papel seco. Os rolos foram colocados em germinador à temperatura de $25^{\circ} \mathrm{C}$ e, as contagens foram realizadas no quinto e no oitavo dia após a semeadura, sendo os resultados expressos em porcentagem de plântulas normais. Primeira contagem da germinação (PCG): realizado conjuntamente ao teste de germinação, sendo a contagem das plântulas normais executada aos cinco dias após a semeadura. Os resultados foram expressos em porcentagem de plântulas normais. Testede frio(TF): conduzido com quatro subamostras de 50 sementes para cada repetição distribuídas uniformemente em rolo de papel tipo germitest umedecido, previamente, com água destilada na proporção de 2,5 vezes a massa do papel seco. Em seguida os rolos de papel foram colocados em sacos plásticos, os quais foram vedados e mantidos em câmara de BOD, regulada à temperatura de $10 \pm 1{ }^{\circ} \mathrm{C}$ durante sete dias. Após esse período, os rolos foram retirados dos sacos plásticos e transferidos para um germinador e mantidas nas mesmas condições do teste de germinação, sendo avaliada a porcentagem de plântulas normais após cinco dias (CÍCERO; 
VIEIRA, 1994). Envelhecimento acelerado (EA): realizado com quatro repetições, utilizando-se o método de gerbox, onde as sementes foram espalhadas em camada única sobre uma tela metálica suspensa dentro de caixas de gerbox, contendo 40 $\mathrm{mL}$ de água destilada ao fundo. Posteriormente, as caixas foram tampadas e acomodadas em câmara BOD, a $41^{\circ} \mathrm{C}$ por $48 \mathrm{~h}$ (MARCOS FILHO, 2005). Após este período as sementes foram colocadas para germinar conforme metodologia descrita para o teste de germinação, e avaliados no quinto dia, sendo os resultados expressos em porcentagem de plântulas normais. Comprimento de plântula (CP): realizado com quatro subamostras de 20 sementes para cada unidade experimental, que foram dispostas alinhadas na parte superior do papel de germinação tipo germitest, umedecido a 2,5 vezes a sua massa seca. Os rolos de papel foram acondicionados em germinador a $25^{\circ} \mathrm{C}$. A leitura foi realizada aos cinco dias após a semeadura, com auxílio de régua graduada em milímetros, sendo medido o comprimento total e da parte aérea de dez plântulas normais aleatoriamente. $\mathrm{O}$ comprimento da raiz foi determinado pela subtração do comprimento total pelo comprimento da parte aérea. Os comprimentos médios da parte aérea e da raiz foram determinados somando-se as medidas de cada repetição e dividindo pelo número de plântulas avaliado, conforme metodologia descrita por (NAKAGAWA, 1999). Emergência a campo (EC): foram semeadas 200 sementes distribuídas em quatro subamostras de 50 sementes para cada repetição, sendo a semeadura realizada em canteiros. A avaliação foi realizada em contagem única das plântulas normais aos 21 dias após a semeadura, sendo os resultados expressos em percentagem (NAKAGAWA, 1999). Massa de 1000 sementes: para esta determinação, foram tomadas oito repetições contendo cada uma 100 sementes pesadas em balança analítica, determinando-se a massa de 1000 sementes, de acordo com o indicado nas Regras para Análise de Sementes - RAS (BRASIL, 2009).

Os dados foram submetidos à análise de variância e havendo significância foi realizado regressão polinomial, a 5\% de probabilidade. Dados em porcentagem oriundos da qualidade fisiológica foram submetidos à transformação arc.sen (raiz $\mathrm{x} / 100$ ). Para a análise estatística foi utilizado o Sistema de Análise Estatística Winstat versão 1.0 (MACHADO; CONCEIÇÃO, 2003).

\section{Resultados e Discussão}

Nas Tabelas 1 e 2 estão apresentados os resultados da ANOVA, das cultivares de soja BMX Turbo RR e NA 5909 RR, respectivamente. Os dados referentes ao número total de legumes na haste principal e o número total de sementes por planta, não apresentaram diferença significativa para ambas cultivares utilizadas, contrariando os resultados obtidos por Pereira Junior et al. (2010), que verificaram aumento no números de legumes conforme o aumento das doses de Si aplicados no sulco por ocasião da semeadura. Para a qualidade fisiológica das sementes, as variáveis germinação, teste de frio, envelhecimento acelerado, comprimento de raiz e emergência em campo não apresentaram efeitos significativos com a aplicação das doses de silício. Para as demais variáveis agronômicas e de qualidade que apresentaram efeitos significativos em função das doses de Si foi realizado regressão polinomial. 
Tabela 1. Quadrados Médios (Q.M.) obtidos na Análise de variância da aplicação de doses de silício via solo da Cultivar BMX Turbo RR.

\begin{tabular}{|c|c|c|c|c|c|c|c|c|c|}
\hline \multirow{2}{*}{ FV } & \multirow{2}{*}{ GL } & \multicolumn{8}{|c|}{ Q.M. } \\
\hline & & PCG & G & $\mathrm{TF}$ & EA & CPA & CR & EC & P.1000 \\
\hline Dose & 4 & $21,3^{*}$ & $5,7^{\mathrm{ns}}$ & $5,32^{\text {ns }}$ & $7,25^{\mathrm{ns}}$ & $3,704^{*}$ & $0,196^{\mathrm{ns}}$ & $3,675^{\text {ns }}$ & $185,58^{*}$ \\
\hline Bloco & 3 & 12,1 & 11,53 & 6,6 & 10,05 & 0,48 & 0,64 & 1,13 & 8,4 \\
\hline Resíduo & 12 & 4,3 & 3,03 & 5,2 & 6,38 & 0,68 & 0,53 & 1,17 & 4,5 \\
\hline $\mathrm{CV} \%$ & - & 2,2 & 1,8 & 2,5 & 2,8 & 4,4 & 7,4 & 1,1 & 1,1 \\
\hline \multirow{2}{*}{ FV } & GI & \multicolumn{8}{|c|}{ Q.M. } \\
\hline & $\mathrm{OL}_{\mathrm{L}}$ & NTLR & NTSR & NTLH & NTSH & NTLP & NTSP & PSP & - \\
\hline Dose & 4 & $167,6^{*}$ & $663,1^{*}$ & $19,45^{\text {ns }}$ & $123,5^{*}$ & $96,69^{*}$ & $273,39^{\text {ns }}$ & $13,29 *$ & - \\
\hline Bloco & 3 & 17,04 & 18,72 & 7,67 & 37,21 & 0,9 & 5,7 & 1,56 & - \\
\hline Resíduo & 12 & 28,55 & 129,4 & 7,69 & 40,05 & 27,7 & 108,6 & 3,65 & - \\
\hline CV\% & - & 9,5 & 9,1 & 19,2 & 19,3 & 7,2 & 6,4 & 6,1 & - \\
\hline
\end{tabular}

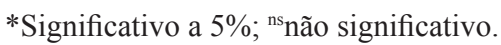

Fonte: Elaboração dos autores.

Tabela 2. Quadrados Médios (Q.M.) obtidos na Análise de variância da aplicação de doses de silício via solo da Cultivar NA5909 RR.

\begin{tabular}{|c|c|c|c|c|c|c|c|c|c|}
\hline \multirow{2}{*}{ FV } & \multirow{2}{*}{ GL } & \multicolumn{8}{|c|}{ Q.M. } \\
\hline & & PCG & $\mathrm{G}$ & $\mathrm{TF}$ & EA & CPA & CR & $\mathrm{EC}$ & P.1000 \\
\hline Dose & 4 & $5,42^{\text {ns }}$ & $4,8^{\text {ns }}$ & $1,625^{\text {ns }}$ & $10,45^{\text {ns }}$ & $0,62^{\text {ns }}$ & $0,157^{\mathrm{ns}}$ & $0,95^{\text {ns }}$ & $81,98^{*}$ \\
\hline Bloco & 3 & 13,9 & 5,7 & 1,1 & 0,9 & 0,51 & 0,14 & 6,8 & 20,80 \\
\hline Resíduo & 12 & 8,05 & 9,7 & 2,7 & 7,6 & 0,48 & 0,11 & 7,2 & 7,26 \\
\hline $\mathrm{CV} \%$ & - & 3,1 & 3,2 & 1,8 & 3,0 & 3,5 & 2,8 & 2,7 & 1,5 \\
\hline \multirow{2}{*}{ FV } & \multirow{2}{*}{ GL } & \multicolumn{8}{|c|}{ Q.M. } \\
\hline & & NTLR & NTSR & NTLH & NTSH & NTLP & NTSP & PSP & - \\
\hline Dose & 4 & $28,31^{\mathrm{ns}}$ & $86,21^{\text {ns }}$ & $1,156^{\text {ns }}$ & $9,987^{\text {ns }}$ & $23,191^{\mathrm{ns}}$ & $47,653^{\text {ns }}$ & $6,1^{\text {ns }}$ & - \\
\hline Bloco & 3 & 12,7 & 60,05 & 8,09 & 39,29 & 3,67 & 19,62 & 1,95 & - \\
\hline Resíduo & 12 & 19,9 & 101,9 & 7,14 & 36,31 & 19,84 & 87,26 & 2,84 & - \\
\hline $\mathrm{CV} \%$ & - & 9,5 & 9,8 & 14,9 & 15,3 & 6,8 & 6,5 & 6,4 & - \\
\hline
\end{tabular}

*Significativo a $5 \%$; ${ }^{\text {ns }}$ não significativo.

Fonte: Elaboração dos autores.

Para o número total de sementes na haste principal os efeitos das doses de Si foram significativos para a cultivar BMX Turbo RR (Figura 1A), ao contrário do que ocorreu para a cultivar NA 5909 RR (Figura 1B). Ocorreu redução no número total de sementes na haste, na cultivar BMX Turbo RR, na ordem de 3,2 sementes para cada unidade de aumento na dose de Si. Tal redução pode ter sido influenciada pelo incremento de produção que ocorreu nos ramos, onde houve acréscimo no número total de legumes e sementes. A planta compensou a redução de produção na haste, distribuindo sua produção nos ramos, não prejudicando assim o rendimento por planta. 
Figura 1. Número total de sementes na haste principal cultivar BMX Turbo RR (A) e NA 5909 RR(B), em plantas produzidas em função da aplicação de silício via solo. Pelotas-RS, Brasil, 2013.
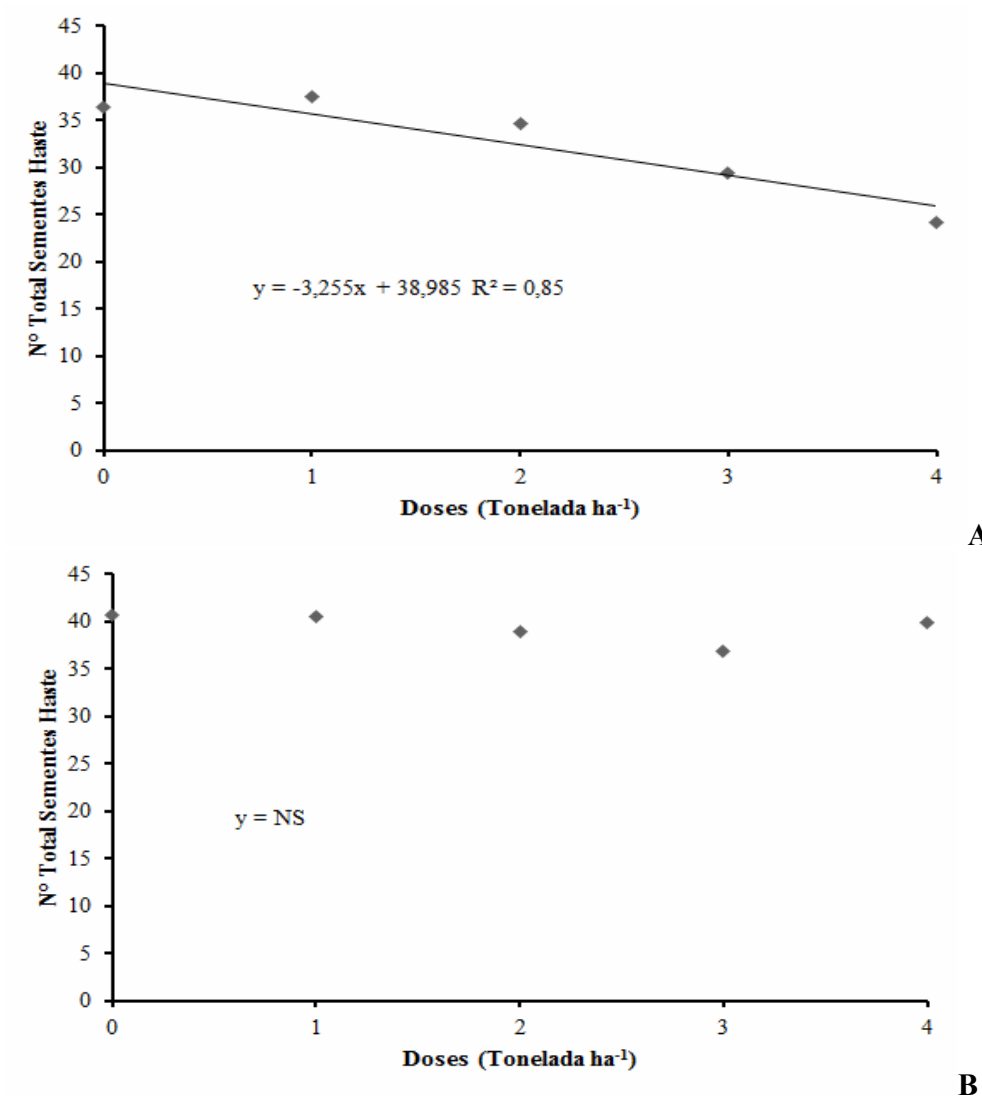

Fonte: Elaboração dos autores.

A aplicação de Si promoveu efeito significativo apenas para a cultivar BMX Turbo RR, nas variáveis número total de legumes nos ramos e número total de sementes nos ramos (Figura 2A e 2C), onde para cada aumento de unidade da dose de Si aplicado (tonelada por ha) ocorreu um incremento de 3,9 legumes nos ramos e de 8,0 sementes nos ramos. No entanto no que se refere a cultivar NA 5909 RR não foi observado efeito significativo com o aumento das doses de Si para nenhuma dessas variáveis (Figura
2B e 2D). Desta forma a resposta à aplicação de silício no solo foi mais evidente na cultivar BMX Turbo RR, que provavelmente devido ao aumento da disponibilidade de $\mathrm{Si}$, resultou em maior número de sementes por planta. Tais resultados são semelhantes aos de Singh, Singh e Singh (2005), que estudando doses e épocas de aplicação de Si em duas colheitas consecutivas de arroz, constataram que a adubação silicatada promoveu aumento no número de panículas por metro quadrado e na produtividade. 
Figura 2. Número total de legumes nos ramos (A) e número total de sementes nos ramos (C) da cultivar BMX Turbo RR e número total de legumes nos ramos (B) e número total de sementes nos ramos (D) da cultivar NA 5909 RR, em plantas produzidas em função da aplicação de silício via solo. Pelotas-RS, Brasil, 2013.
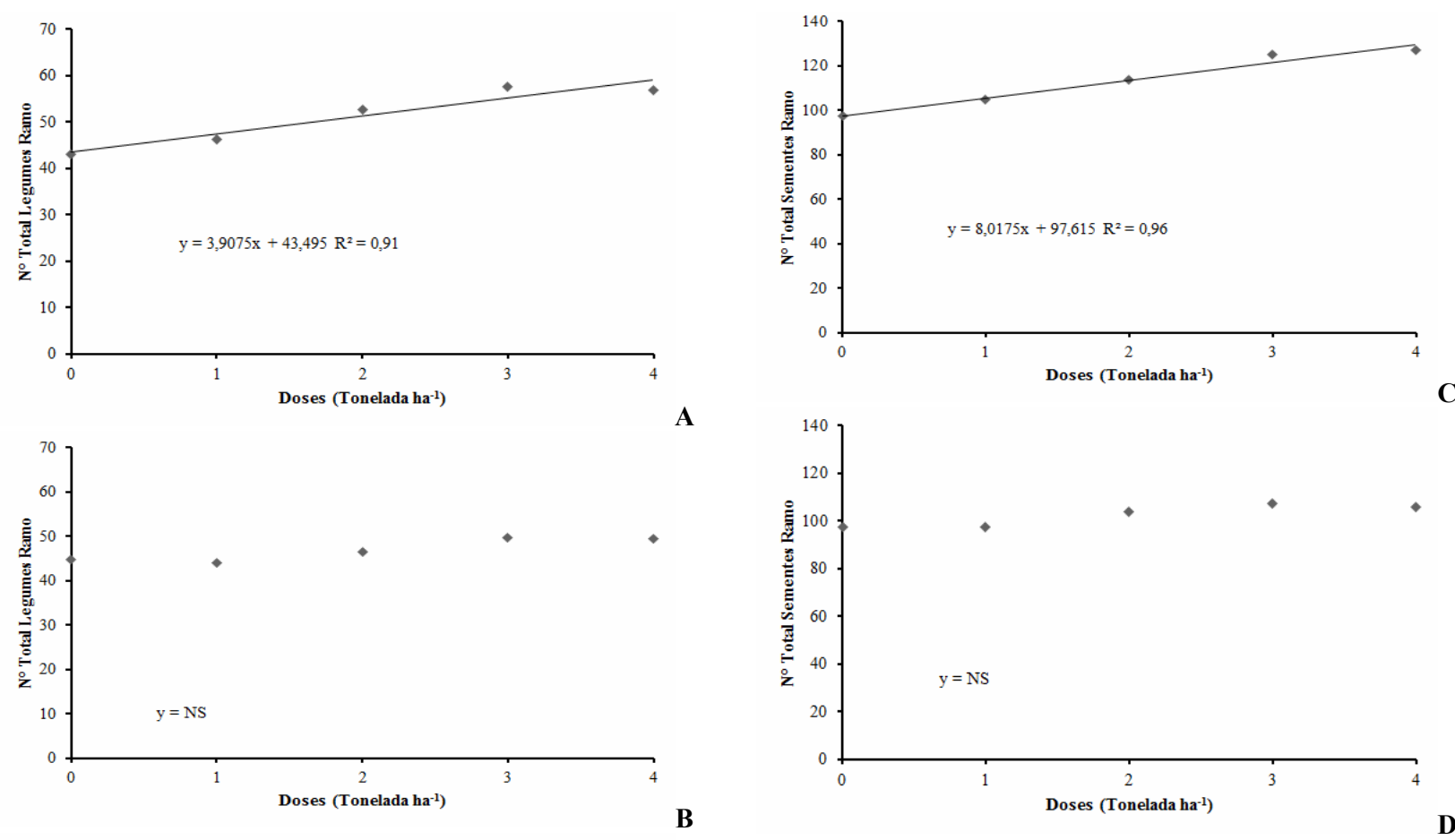

Fonte: Elaboração dos autores.

No que se refere ao número total de legumes por planta, verifica-se incremento na cultivar BMX Turbo RR em resposta ao incremento das doses de $\mathrm{Si}$ (Figura 3A), sendo que os resultados enquadraramse num modelo linear crescente, pois para cada unidade de aumento na dose de Si foi observado um acréscimo de 2,66 legumes. No entanto, na cultivar NA 5909 RR não foi observado efeito significativo das doses de Si aplicada. Pereira Junior et al. (2010), trabalhando com diferentes doses de Si aplicadas nos sulcos de semeadura, observaram que o número de legumes por planta aumentou significativamente com a aplicação de $200 \mathrm{~kg} \mathrm{ha}^{-1}$ de silicato, sendo este um importante componente do rendimento.
A massa de sementes por planta também apresentou resultados significativos apenas para a cultivar BMX Turbo RR (Figura 4A). Os dados observados enquadraram-se em um modelo polinomial quadrático positivo, sendo o ponto de máxima, na dose de $2,55 \mathrm{t} \mathrm{ha}^{-1}$, e este superior a testemunha em 4,58 $\mathrm{g} \mathrm{planta}^{-1}$. No entanto, deve-se destacar que a maior dose $\left(4 \mathrm{tha}^{-1}\right)$ foi superior a testemunha em 3,1 g planta $^{-1}$. Moreira et al. (2010), ao submeterem plantas de soja a três aplicações de silicato de potássio via foliar, observaram incremento de produtividade da ordem de 19 sacas, justificando esse incremento pela maior produção de matéria seca das plantas. 
Figura 3. Número total de legumes por planta, em plantas de soja das cultivares BMX Turbo RR (A) e NA 5909 RR (B), produzidas em função da aplicação de silício via solo. Pelotas-RS, Brasil, 2013.
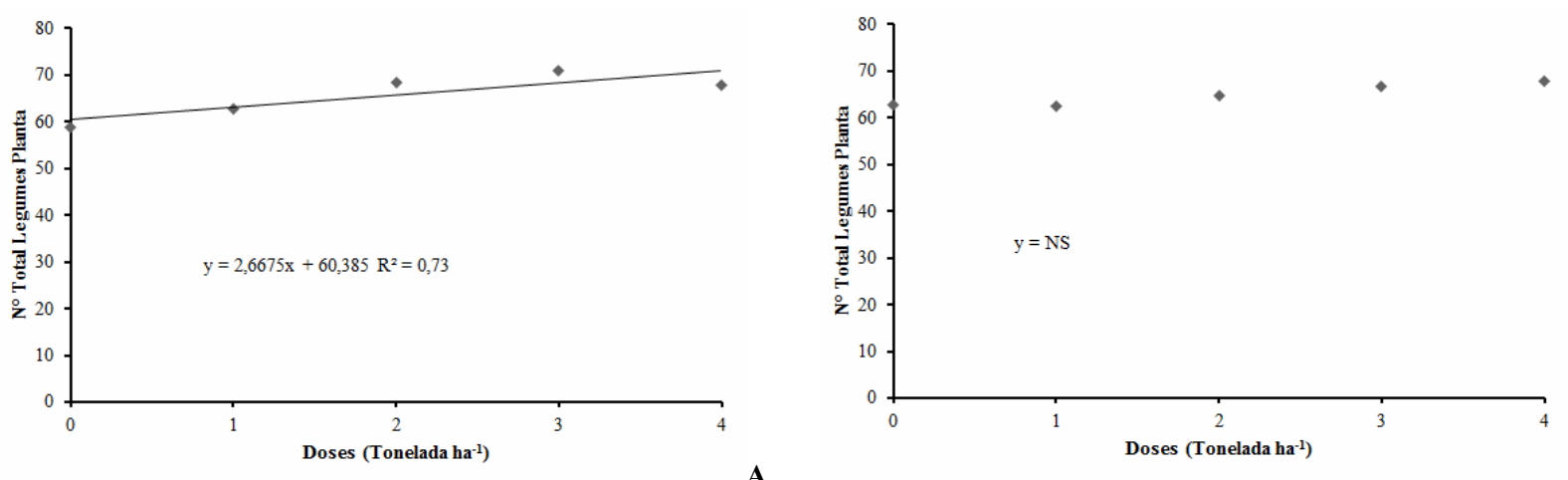

Fonte: Elaboração dos autores.

Figura 4. Massa total de sementes por planta, em plantas de soja das cultivares BMX Turbo RR (A) e NA 5909 RR (B), produzidas em função da aplicação de silício via solo. Pelotas-RS, Brasil, 2013.
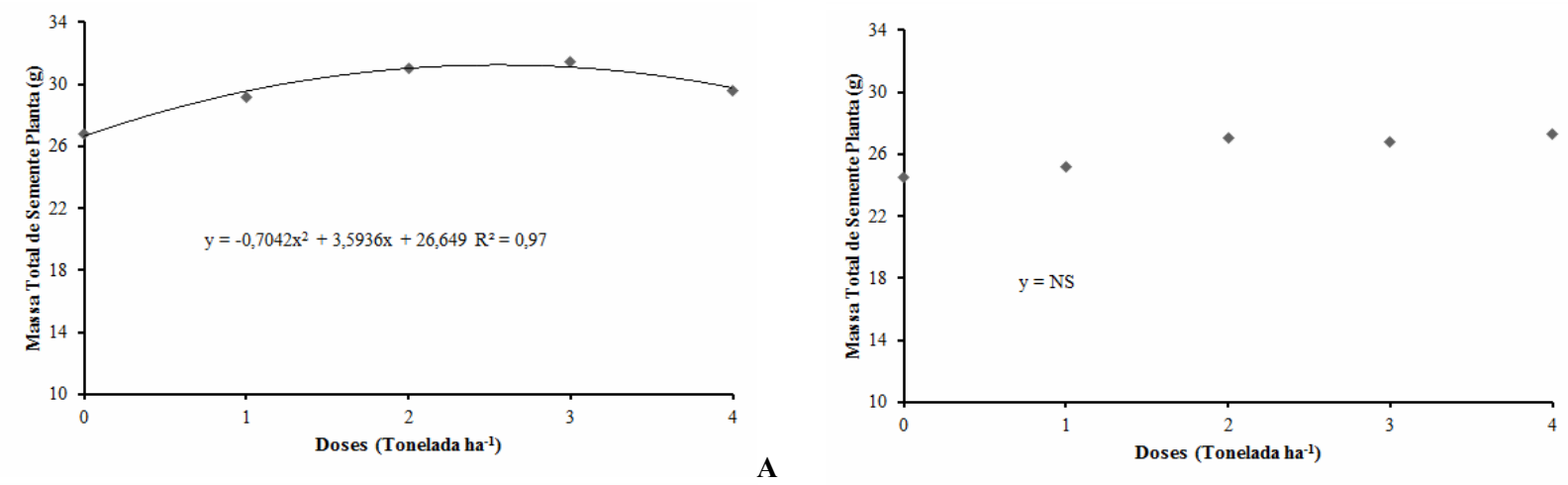

Fonte: Elaboração dos autores.

Resultados encontrados por Balastra et al. (1989), Deren et al. (1994) e Mauad et al. (2003), mostraram que o silicio elevou a massa de sementes de arroz, corroborando com os resultados deste trabalho. Segundo Crusciol et al. (2013), a aplicação de silício via foliar aumentou o número de vagens por planta, sendo o incremento de $11 \%$, o que refletiu diretamente na produtividade de grãos, com incremento de $353 \mathrm{~kg} \mathrm{ha}^{-1}$ (14\%). Desta forma é importante destacar a resposta positiva da aplicação de silício no solo, pois mesmo não promovendo estatisticamente acréscimo na produção da cultivar NA 5909 RR, não prejudicou o desempenho da mesma. Já na cultivar BMX Turbo RR, a aplicação das doses de silício promoveu acréscimos nas principais características agronômicas, o que resultou em maior massa de sementes por planta.

Observa-se na Figura 5 que os resultados das duas cultivares foram significativo para a massa de mil sementes, sendo que ambas apresentaram comportamento semelhante, enquadrando-se em um modelo polinomial quadrático positivo. $\mathrm{Na}$ Figura 5A que se refere a cultivar BMX Turbo RR, a massa de mil sementes obteve incremento até a dose de 1,67 tha-1 , e para a cultivar NA 5909 RR (Figura $5 \mathrm{~B})$ obteve incremento na massa de mil sementes, 
até a dose de 2,32 t ha-1. Resultados semelhantes foram encontrados por Bussolaro, Zelin e Simoneti (2011), que observaram aumentos de produtividade, quando aplicado silício via foliar na dosagem média de $0,82 \mathrm{~L} \mathrm{ha}^{-1}$. No entanto, para Juliatti et al. (2004), as doses de silicato de cálcio em pó e granulado aplicados, não promoveu diferença significativa na massa de mil sementes e no rendimento. A massa de mil sementes é um importante indicador de qualidade que pode resultar em aumento de produtividade, pois sementes mais pesadas resultam em maior rendimento. Ainda segundo Carvalho e Nakagawa (2000), a massa de mil sementes varia de acordo com o genótipo, mas também é influenciada pelas condições ambientais e práticas de manejo, como a nutrição das plantas. Neste caso, observouse influencia das doses de silicio na massa de mil sementes, indicando que pode haver aumento na produtividade, pois alem, de proporcionar aumento no número de sementes por planta, proporcionou incremento na massa de mil sementes para ambas cultivares.

Figura 5. Massa de mil sementes, de sementes de soja das cultivares BMX Turbo RR (A) e NA 5909 RR (B), produzidas em função da aplicação de silício via solo. Pelotas-RS, Brasil, 2013.

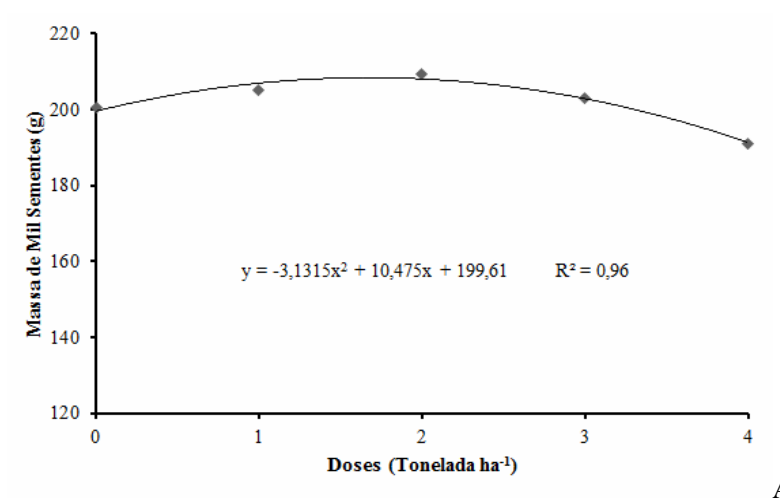

$\mathbf{A}$

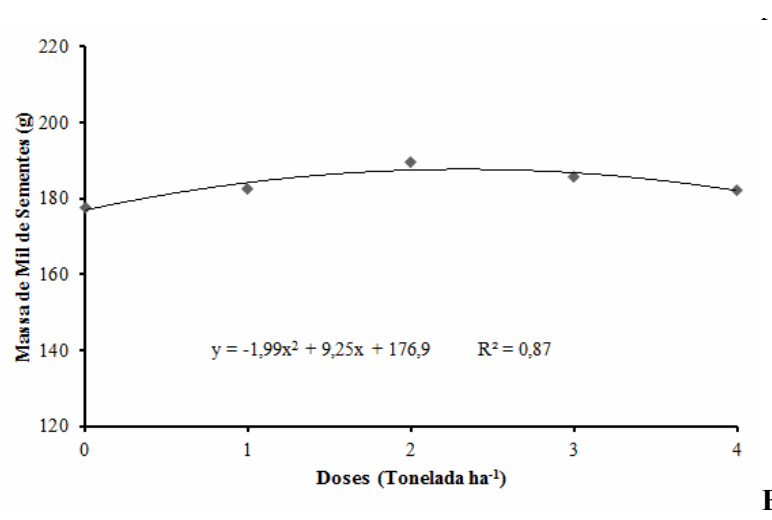

Fonte: Elaboração dos autores.

Em relação a qualidade fisiológica das sementes, para os dados referentes aos testes de germinação, teste de frio, envelhecimento acelerado, emergência em campo e comprimento de raiz, de sementes de soja produzidas com aplicações de doses de $\mathrm{Si}$, das cultivares BMX Turbo RR e NA 5909 RR, não foi observado efeito significativo de doses de Si para essas variáveis. Cabe ainda salientar a qualidade das sementes produzidas, uma vez que os testes de vigor como o teste de frio e de envelhecimento acelerado apresentaram valores elevados (92\% e 90\%) respectivamente e que a emergência em campo apresentou valor superior (98\%) ao encontrado no teste de germinação $(96 \%)$ o qual é realizado em condições ideais de temperatura, luz e umidade.
No que se refere a primeira contagem de germinação e comprimento da parte aérea, constatou-se efeito significativo para as doses de Si aplicado, sendo então realizada regressão polinomial e os resultados apresentados na Figura 6 e 7, respectivamente. Para a primeira contagem da germinação, apenas a cultivar BMX Turbo RR (Figura 6A) apresentou incremento com o aumento das doses, na ordem de 1,45 pontos percentuais para cada unidade de aumento nas doses de Si. Resultado similar foi observado por Matichenkov et al. (2005), que trabalhando com doses de Si em trigo, verificaram aumento linear de plântulas normais no teste de germinação e primeira contagem de germinação com o incremento das doses de Si. Na 
Figura 6B os resultados da cultivar NA 5909 RR, não foram significativos, no entanto, todos os valores observados estão acima de $90 \%$ demonstrando a alta qualidade fisiológica das sementes. Essa diferença de comportamento mostrado pelas cultivares pode ser explicada pela possível diferença de origem genética existente entre elas, além disso, de acordo com Oliveira et al. (2003), existem diferença na eficiência de utilização de nutrientes entre genótipos.

Figura 6. Porcentagens de plântulas normais obtidas no teste de primeira contagem de germinação de sementes de soja das cultivares BMX Turbo RR (A) e NA 5909 RR(B), produzidas em função da aplicação de silício via solo. Pelotas-RS, Brasil, 2013.

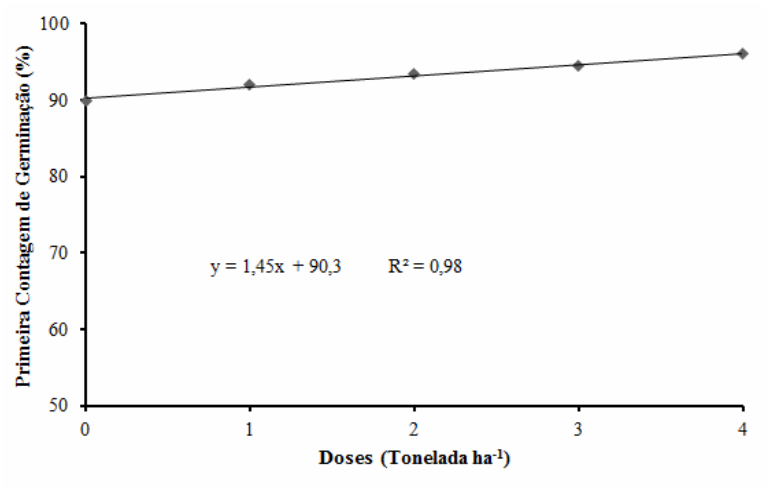

$\mathbf{A}$

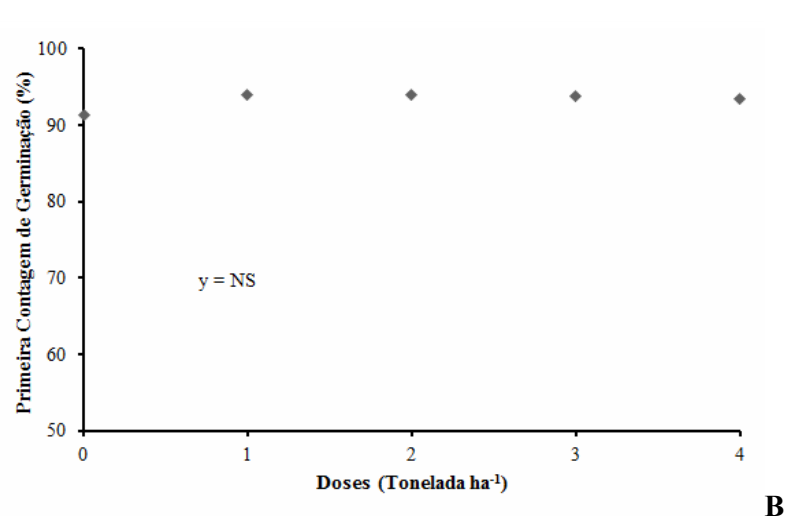

Fonte: Elaboração dos autores.

Para a variável comprimento de parte aérea de plântulas, observou-se que os resultados foram significativos apenas para a cultivar BMX Turbo RR (Figura 7A), sendo os resultados lineares crescentes na ordem de 0,59 centímetros para cada tonelada a mais de Si. Essa resposta mostra aumento da qualidade das sementes avaliada neste teste, pois com o aumento das doses houve acréscimo no tamanho da parte aérea das plântulas. Plântulas com maior crescimento inicial podem gerar plantas mais produtivas, uma vez que a maior área foliar inicial pode proporcionar maior taxa fotossintética, pois segundo Gustafson, Gibson e Nickrent (2004), plantas portadoras de elevada velocidade de emergência e de crescimento inicial, possuem prioridade na utilização dos recursos do meio e, por isso, geralmente levam vantagem na utilização desses.
Segundo estudo realizado por Lima (1998) ocorrem diferenças varietais significativas em relação a absorção de Si por plantas de soja. Tais diferenças de absorção podem justificar os resultados deste trabalho, quando em várias análises foram encontradas respostas diferentes entre as cultivares, principalmente no número de legumes e na massa de sementes por planta da cultivar BMX Turbo RR, na qual foi observado incremento nestas variáveis com o aumento das doses de Si. É importante destacar que a aplicação de Si, além de proporcionar aumento da massa de sementes por plantas, não prejudicou a qualidade fisiológica das sementes produzidas. De maneira semelhante o uso de argila silicatada via foliar e em sulco não interferiu na qualidade fisiológica das sementes e teve diferentes respostas em produtividade nos genótipos de trigo estudados (LIMA, 2010). Ainda de acordo com Harter e Barros (2011), a aplicação de cálcio e Si via foliar em plantas de soja resultou em maior qualidade fisiológica das sementes. 
Figura 7. Comprimento da parte aérea de plântulas de soja, das cultivares BMX Turbo RR (A) e NA 5909 RR (B), produzidas em função da aplicação de silício via solo. Pelotas-RS, Brasil, 2013.

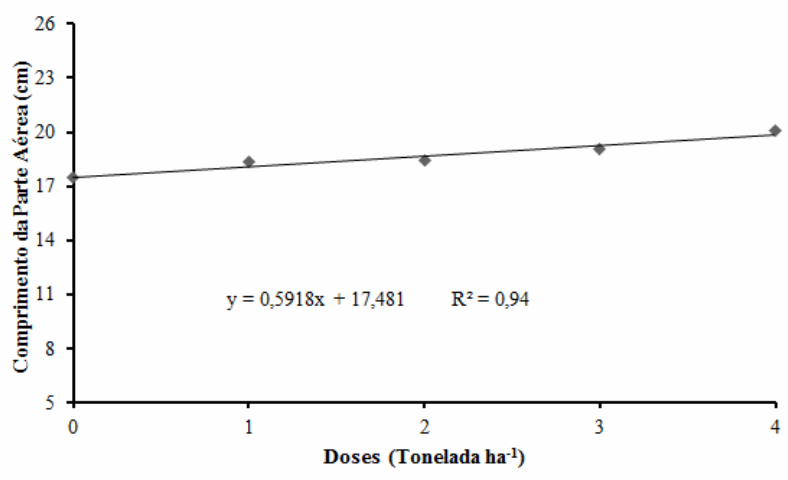

A

Fonte: Elaboração dos autores.

\section{Conclusões}

A aplicação de silício via solo é benéfico para a cultura da soja, melhorando as características agronômicas e aumentando a massa de sementes por planta na cultivar de soja BMX Turbo RR. A massa de massa de mil sementes é influenciado positivamente até a dose de $1,67 \mathrm{tha}^{-1}$ para a cultivar BMX Turbo RR e até a dose de 2,32 $\mathrm{t} \mathrm{ha}^{-1}$ para a cultivar NA 5909 RR. O vigor das sementes da cultivar BMX Turbo RR é incrementado com o uso de silício.

\section{Referências}

BALASTRA, M. L. F.; PEREZ, C. M.; JULIANO, B. O.; VILLREAL, P. Effects of sílica level on some properties of Oryza sativa straw and hult. Canadian Journal Botanic, Ottawa, v. 67, p. 2356-63, 1989.

BECKWITH, R. S.; REEVE, R. Studies on soluble silica in soils. 1-The sorption of silicon acid by soils and minerals. Australian Journal Soil Research, Melbourne, v. 1, n. 3, p. 157-168, 1963.

BRASIL. Ministério da Agricultura, Pecuária e Abastecimento. Regras para análise de sementes. Brasília: Mapa/ACS, 2009. 399 p.

BUSSOLARO, I.; ZELIN, E.; SIMONETI, A. P. M. M. Aplicação de silício no controle de percevejos e produtividade da soja. Cultivando o Saber, Cascavel, v. 4, n. 3, p. 9-19, 2011.

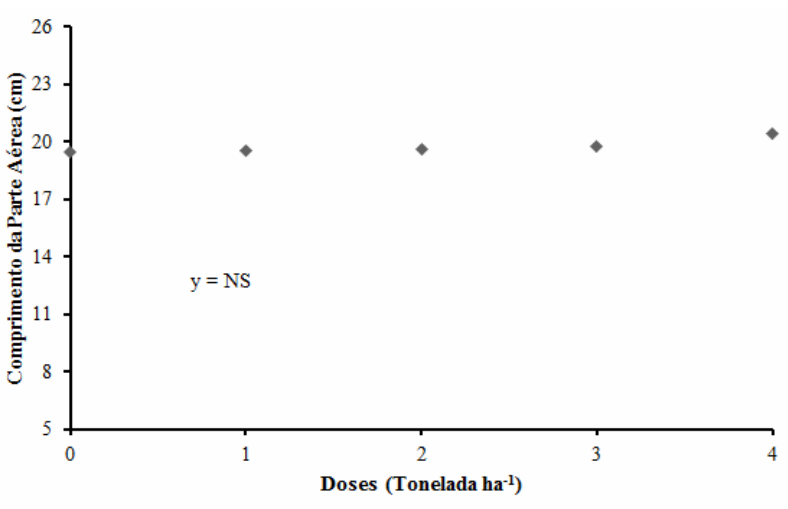

B

CARVALHO, N. M.; NAKAGAWA, J. Sementes: ciência, tecnologia e produção. 4. ed. Jaboticabal: Funep, 2000. $588 \mathrm{p}$.

CHÉRIF, M.; ASSELIN, A.; BELEANGER, R. R. Defense responses induced by soluble silicon in cucumber roots infected by Pythim spp. Phytopathology, St. Paul, v. 84, n. 3, p. 236-242, 1994.

CÍCERO, S. M.; VIEIRA, R. D. Teste de frio. In: VIEIRA, R. D.; CARVALHO, N. M. (Ed.) Testes de vigor em sementes. Jaboticabal: FUNEP, 1994. p. 151164.

COMISSÃO DE QUÍMICA E FERTILIDADE DO SOLO - CQFS RS/SC. Manual de adubação e de calagem para os estados do Rio Grande do Sul e de Santa Catarina. 10. ed. Porto Alegre: NRS/SBCS, 2004. 400 p.

COMPANHIA NACIONAL DE ABASTECIMENTO - CONAB. Acompanhamento de safra brasileira: sexto levantamento grãos safra 2014/2015. Brasília: Observatório Agrícola, 2015. p. 1-103. Disponível em: $\quad<$ http://www.conab.gov.br/OlalaCMS/uploads/ arquivos/15_03_10_09_00_11_boletim_graos_ marco_2015.pdf $>$. Acesso em: 11 mar. 2015.

CRUSCIOL, C. A. C.; SORATTO, R. P.; CASRO, G. S. A.; COSTA, C. H. M.; FERRARI NETO, J. Aplicação foliar de ácido silícico estabilizado na soja, feijão e amendoim. Ciência Agronômica, Fortaleza, v. 44, n. 2, p. 404-410, 2013.

DEREN, C. W.; DATNOFF, L. E.; SNYDER, G. H.; MARTIN, F. G. Silicon concentration, disease response, and yield components of rice genotypes grown on flooded organic histosols. Crop Science, Madison, v. 34, n. 2, p. 733-737, 1994. 
EPSTEIN, E. The anomaly of silicion in plant biology. Proceeding National Academic Science, Washington, v. 91, p. 11-17, 1994.

FEHR, W.; CAVINESS, R. H. Stages of soybean development. Special Report 80. Iowa: Iowa State University Ames, 1977. 12 p.

FREITAS, L. C.; COSTA FILHO, J. F. da; ALOISI, R. R.; MELO, W. J. Contribuição ao estudo da sílica solúvel em alguns perfis de solos. Cientifica, Jaboticabal, v. 5, n. 2, p. 296-305, 1977.

GUNES, A.; PILBEAM, D. J.; INAL, A.; COBAN, S. Influence of silicon on sunflower cultivars under drought stress, in growth, antioxidant mechanisms, and lipid peroxidation. Comunication in Soil Science and Plant Amalysis, v. 39, n. 13-14, p. 1885-1903, 2008.

GUSTAFSON, D. J.; GIBSON, D. J.; NICKRENT, D. L. Competitive relationships of Andropogon gerardii (Big Bluestem) from remnant and restored native populations and select cultivated varieties. Functional Ecology, London, v. 18, n. 3, p. 451-457, 2004.

HARTER, F. S.; BARROS, A. C. S. A. Cálcio e silício na produção e qualidade de sementes de soja. Revista Brasileira de Sementes, Londrina, v. 33, n. 1, p. 54-60, 2011.

JULIATTI, F. C.; PEDROSA, M. G.; LANNA, R. M. Q.; BRITO, S. H.; MELO, B. Influência do silício na redução de podridão de sementes por usarium semitectum na cultura da soja. Bioscience Journal, Uberlândia, v. 20, n. 2, p. 57-63, 2004.

. Vigor de sementes e competição intra-específica em soja. Ciência Rural, Santa Maria, v. 35, n. 6, p. 12481256, 2005.

KOLCHINSKI, E. M.; SCHUCH, L. O. B.; PESKE, S. T. Crescimento inicial de soja em função do vigor das sementes. Revista Brasileira de Agrociência, Pelotas, v. 12, n. 2, p. 163-166, 2006.

LIMA, B. A. D. Uso da argila silicatada como fonte de silicio na produção de sementes de cereais. 2010. Tese (Doutorado em Ciência e Tecnologia de Sementes) Faculdade de Agronomia Eliseu Maciel, Pelotas.

LIMA, M. T. G. Interrelação cancro da haste (Diaporthe phaseolorum f. sp. meridionalis), nodulação (Bradyrhizobium japonicum) e Si em soja (G1vcine Max (L) Merril). 1998. Tese (Doutorado em Energia Nuclear na Agricultura) - Escola Superior de Agricultura Luiz de Queiroz, Piracícaba.
MA, J. F.; MIYAKE, Y.; TAKAHASHI, E. Silicon as a beneficial element for crop plant. In: DATNOFF, L. E.; KORNDÖRFER, G. H.; SNYDER, G. (Ed.). Silicon in agriculture. New York: Elsevier Science, 2001. p. 17-39.

MACHADO, A. A.; CONCEIÇÃO, A. R. Sistema de análise estatística para Windows. Winstat. Versão 1. 0. Pelotas: UFPel, 2003.

MALAVOLTA, E. Manual de nutrição mineral de plantas. São Paulo: Editora Agronômica Ceres, 2006. $638 \mathrm{p}$.

MARCOS FILHO, J. Fisiologia de sementes de plantas cultivadas. Piracicaba: FEALQ, 2005. 495 p.

MARSCHNER, H. Mineral nutrition of higher plants. $2^{\text {th }}$ ed. London: Academic, 1995. 889 p.

MATICHENKOV, V. V.; KOSOBRUKHOV, A. A.; SHABNOVA, N. I.; BOCHARNIKOVA, E. A. Plant response to silicon fertilizers under salt stress. Agrokhimiya, Moscow, v. 10, p. 59-63, 2005.

MAUAD, M.; GRASSI FILHO, H.; CRUSCIOL, C. A. C.; CORREAA, J. C. Teores de silício no solo e na planta de arroz de terras altas com diferentes doses de adubação silicatada e nitrogenada. Revista Brasileira de Ciência do Solo, Viçosa, v. 27, n. 5, p. 867-873, 2003.

MOREIRA, A. R.; FAGAN, E. B.; MARTINS, K. V.; SOUZA, C. H. E. Resposta da cultura de soja a aplicação de silício foliar. Bioscience Journal, Uberlândia, v. 26, n. 3, p. 413-423, 2010.

MORI, C.; BERTAGNOLI, P. F.; MORAES, R. M. A. de; COSTAMILAN, L. M.; IGNACZAK, J. C.; ROESSING, A. C.; LANGE, C.; MENEZES, V. G.; FISCHER, M. M. Levantamento de uso de tecnologias em lavouras de soja na metade sul do estado do Rio Grande do Sul. In: COSTAMilan, L. M.; BertagnOlli, P. F.; MORAES, R. M. A. de. (Org.). Soja: resultados de pesquisa 2005/2006. EMBRAPA. Centro Nacional de Pesquisa de Trigo. Passo Fundo: Embrapa Trigo, 2006. p. 222-271. (Embrapa Trigo. Documentos, 68).

MYAKE, Y.; TAKAHASHI, E. Effect of silicon on the growth of soybean in a solution culture. Soil Science and Plant Nutrition, Tókio, v. 31, n. 4, p. 625-636, 1985.

NAKAGAWA, J. Testes de vigor baseados no desempenho das plântulas. In: KRZYZANOWSKI, F. C.; VIEIRA, R. D.; FRANÇA-NETO, J. B. Vigor de sementes: conceitos e testes. Londrina: ABRATES, 1999. cap. 2, p. 9-13.

NUNES, J. C. Tratamento de semente: qualidade e fatores que podem afetar a sua performance em laboratório. São Paulo, Syngenta Proteção de Cultivos Ltda., 2005. 16 p. 
OLIVEIRA, S. C.; COSTA, M. C. G.; CHAGAS, R. C. S.; FENILLI, T. A. B.; HEINRICHS, R.; CABRAL, C. P.; MALAVOLTA, E. Resposta de duas cultivares de arroz a doses de zinco aplicado como oxissulfato. Pesquisa Agropecuária Brasileira, Brasileira, v. 38, n. 3, p. 387-396, 2003.

PEREIRA, H. S.; KORNDÖFER, G. H.; VIDAL, A. A.; CAMARGO, M. S. Silicon sources for the rice plants. Scientia Agricola, Piracicaba, v. 61, n. 5, p. 522-528, 2004.

PEREIRAJUNIOR, P.; REZENDE, P. M.; MALFITANO, S. C.; LIMA, R. K.; ORREAA, L. V. T. Efeito de doses de silício sobre a produtividade e características agronômicas da soja [Glycine $\max$ (L.) Merrill]. Ciência e Agrotécnologia, Lavras, v. 34, n. 4, p. 908-913, 2010.

RAIJ, B. V.; CAMARGO, O. A. Sílica solúvel em solos. Bragantia, Campinas, v. 32, n. 11, p. 223-231, 1973.

RAVEN, J. A. The transport and function of silicon in plant. Biological Reviews, Cambridge, v. 58, n. 2, p. 179207, 1983.

REIS, T. H. P.; GUIMARÃES, P. T. G.; FIGUEREDO, F. C.; POZZA, A. A. A.; NOGUEIRA, F. D.; RODRIGUES, C. R. O silício na nutrição e defesa de plantas. Belo Horizonte: EPAMIG, 2007. 124 p. (Boletim técnico, 82).
SÁ, M. E. Importância da adubação na qualidade de semente. In: SÁ, M. E.; BUZZETI, S. (Ed.). Importância da adubação na qualidade dos produtos agrícolas. São Paulo: Ícone, 1994. p. 65-98.

SANTOS, D. M. M. Nutrição mineral. Jaboticabal: UNESP, 2004. 13 p. (Apostila de Fisiologia Vegetal).

SINGH, A. K.; SINGH, R.; SINGH, K. Growth, yield and economics of rice (Oryza sativa) as influenced by level and time of silicon application. Indian Journal of Agronomy, New Delhi, v. 50, n. 3, p. 190-193, 2005.

STRECK, E. V.; KÄMPF, N.; DALMOLIN, R. S. D.; KLAMT, E.; NASCIMENTO, P. C.; SCHNEIDER, P.; GIASSON, E.; PINTO, L. F. S. Solos do Rio Grande do Sul. 2. ed. Porto Alegre: EMATER/RSASCAR, 2008. p. 222.

WIESE, H.; NIKOLIC, M.; RÖMEHELD, V. Silicon in plant nutrition - effects on zinc, manganese and boran leaf concentrations and compartmentation. In: SATTELMACHER, B.; HORST, W. J. (Ed.). The apoplast of higher plants: compartment of storage, transport and reactions. London: Springer, 2007. p. 3347. 